\title{
Reasoning of the Model Sizes in Modeling the Interaction between Tool and Rock
}

\author{
Vladimir Aksenov ${ }^{1,3^{*}}$, Vladimir Sadovets ${ }^{2,3}$, and Dmitriy Pashkov ${ }^{1}$ \\ ${ }^{1}$ Siberian Branch of the Russian Academy of Sciences Federal Centre for Coal and Coal Chemistry \\ Studies Coal Institute 650610, Russia, Kemerovo, Leningradskiy Avenue, 10. \\ ${ }^{2}$ T.F. Gorbachev Kuzbass State Technical University, Department of Informational and Automated \\ Production Systems, 650000 Kemerovo, 28 Vesennya st., Russian \\ ${ }^{3}$ National Research Tomsk Polytechnic University, Yurga Institute of Technology, Yurga 652050, \\ Yurga, Leningradskaya str., 261.
}

\begin{abstract}
The article proves model sizes for modeling the interaction between tool and rock. The relevance of the research was considered. Information on the analysis of existing executive bodies (EB) used in mining, construction and municipal services is given. The finite element method is described, it was concluded in particular that the ideal model of the interaction of the executive body with the face rock would be a surface conjugated with the working of real dimensions located in an infinite massif or in a massif that is many times larger than the output. To solve the problem, cylindrical workings with a diameter $\mathrm{D}=3.2 \mathrm{~m}$ were used, where the face shape is represented by two-thread helicoidal surfaces, surrounded by an around boundary massif with thickness $\mathrm{B}$ equal to $0.5 \mathrm{D}, \mathrm{D}, 1.5 \mathrm{D}$, $2 \mathrm{D}, 2.5 \mathrm{D}$. The exterior surfaces of the model were fixed, and distributed loads corresponding to the interaction forces arising from the operation of the ETC-2086 bar unit installed on the basis of the MTZ-82 tractor were applied to the face surface. On the basis of the conducted research, the effect of the model size on the pattern of directed differentiated state (DDS) of a face was determined.
\end{abstract}

\section{Introduction}

The formation of the underground space and the development of the Earth's interior are the most important tasks of the modern humankind activity and its future $[1,2]$. The constant growth of urban territories shortage calls for the creation of a new underground infrastructure, which is an effective mean of solving transport, territorial and environmental problems of growing megacities [3].

Existing mining systems and technologies for mining workings do not correspond to the tasks arising in the development of underground space [4].

A promising direction in the development of holes formation technologies in the underground space is the application of technology that we had called a "geowinchester technology", the basic element of which is the geokhod. At present, a prototype of the

\footnotetext{
${ }^{*}$ Corresponding author: 55vva42@mail.ru
} 
geokhod with an executive body for the destruction of medium strength rocks has been created (Figure 1) $[5,6]$.

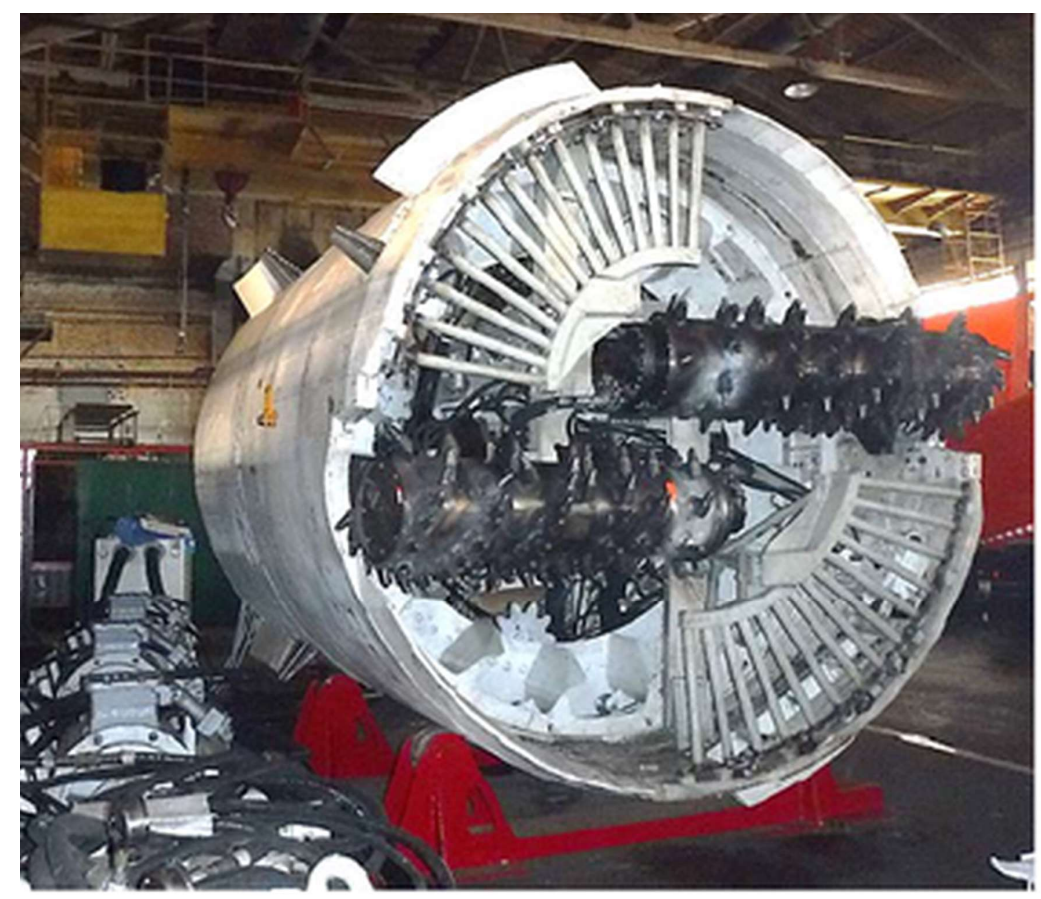

Fig. 1. A Pilot Model of the geokhod with Drum Executive Body (EB).

At the current stage of the development of geowinchester technology elements, there is an urgent need to develop constructive and technical solutions of the executive bodies capable of producing holes in the underground space in rocks with a strength of up to 1 according to Protodyakonov`s scale $[7,8]$.

In $[7,8]$ the analysis of existing executive bodies used in mining, construction and housing and utilities is made. The advantages and disadvantages of these executive bodies are determined. It is also concluded that the use of bar executive bodies for breaking rocks with strength of up to 1 according to Protodyakonov`s scale in geowinchester technology is a promising and urgent task.

A deterrent factor in the use of geokhod for hole formation in the underground space in rocks with a strength of up to 1 is the lack of sound technical and design solutions, methods for calculating and designing of bar executive bodies for these rocks destruction.

Therefore, the work aimed at developing the bar executive bodies of geokhod to destroy rocks with a strength of up to 1 are relevant.

Finite element method. When designing machines, building structures, technological processes in scientific research, software complexes of computer-aided engineering analysis (CEA) based on the finite element method (FEM) are widely used today. They allow us to solve numerically a wide variety of problems from such areas of physics as the mechanics of a rigid deformable body, the mechanics of a fluid and gas, heat transfer, and electrodynamics. It is possible to solve related problems. There are specialized packages based on FEM, which are designed for certain technical applications.

To use these advanced software tools effectively, you need to know not only the theory of the physical process being studied, but also to know the theory of FEM. 
The finite element method (FEM) is a method of approximate numerical solution of physical problems.

The essence of this method consists in replacing the object under investigation with a discrete model in the form of a set of individual subregions with known properties, called finite elements (FEs), which are interconnected at individual points-nodes. As the soughtfor values, the displacement, effort, temperature, etc. are used in these nodes.

To assess the influence of the geometrical parameters of the EB on the conditions of its operation, it is necessary to solve complex problems of contact interactions of elastic bodies. To solve contact problems, the finite element method is successfully applied; there are software tools for automating the solution of contact problems using the finite element method $[9,10]$.

To exclude the effect of fixed surfaces on simulation results, the working of real dimensions should be located in an infinite massif, or in a massif that is many times larger than the output.

In addition to the size of the around boundary massif, the accuracy of modeling is influenced by the size of the finite elements (grid density) into which the models are divided. With the increase in grid density and the increase in the size of the model, the accuracy of simulation results is increased, but the CPU time and hardware requirements are increasing. And conversely, when the density of the grid is reduced and the model size is reduced, the complexity of processing results is reduced, but quality deteriorates.

\section{Methods of research}

The initial conditions for the working models were the conditions for the use of a $3.2 \mathrm{~m}$ diameter geokhod. To determine the optimum proportions of the size of the working and the around boundary massif, comparative studies of the stressed states of the faces of cylindrical workings with a diameter of $\mathrm{D}=3.2 \mathrm{~m}$ were carried out, where the face shape is represented by two-thread helicoidal surfaces surrounded by the around boundary massif $\mathrm{B}$ with thickness equal to $0.5 \mathrm{D}, \mathrm{D}, 1.5 \mathrm{D}, 2 \mathrm{D}, 2.5 \mathrm{D}(1.6 \mathrm{~m}, 3.2 \mathrm{~m}, 4.8 \mathrm{~m}, 6.4 \mathrm{~m}, 8 \mathrm{~m})$.

When modeling the working of clay soil, which is typical for the Kemerovo region, at a depth of $30 \mathrm{~m}$ were studied [11].

Physical and mechanical properties of the rock [11]:

Density $\rho=1900 \mathrm{~kg} / \mathrm{m}^{3}$

Coefficient of strength according to Protodjakonov`s scale $\mathrm{f}=1$

Compression Strength under uniaxial compression $\sigma \mathrm{c}=11.2 \mathrm{MPa}$

Tensile strength under uniaxial tension $\sigma \mathrm{p}=0.2 \mathrm{MPa}$

Coupling (ultimate strength at clean cut) $\tau=0.05 \mathrm{MPa}$

The Young's modulus $\mathrm{E}=59 \mathrm{MPa}$

The Shear Module G $=28.7 \mathrm{MPa}$

Poisson`s ratio $\mu=0.27$

Models were divided into three-dimension 6-node elements; face surface was broken into elements of $50 \mathrm{~mm}$ in size, the rest of the massif per $500 \mathrm{~mm}$ element. The transition of the dimensions of the element from 50 to $500 \mathrm{~mm}$ was carried out gradually on eight transition layers [9].

The exterior surfaces of the model (Fig. 2) were fixed, and distributed loads were applied to the face surface, which corresponded to the interaction forces arising from the operation of the ETC-2086 bar mounted on the MTZ-82 tractor. 

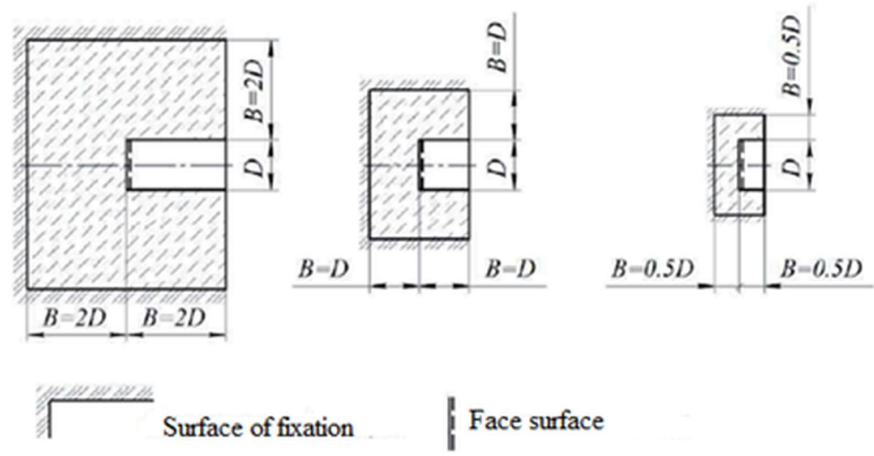

Face surface

Fig. 2. Variants of models with different sizes of an around boundary massif.

To two radially extended rectangular benches with a width of $400 \mathrm{~mm}$ (Fig. 3), a normal distributed load with meaning $q_{n}=5.1 \times 10^{4} \mathrm{~Pa}$ and the corresponding distributed load $q_{t}=5.1 \times 10^{5} \mathrm{~Pa}$ were applied.

\section{Results}

An assessment of the effect of the fixed surface of the model (Fig. 2) on the pattern of directed differentiated state (DDS) of a face was carried out. The values of the following stresses were determined:

- minimum (negative) $\sigma_{3}$ (Fig. 4) and maximum (positive) $\sigma_{3}$ (Fig. 4), are characteristic for the face space part;

$-\sigma_{3}$ on the surface of models fixation (Fig. 3).

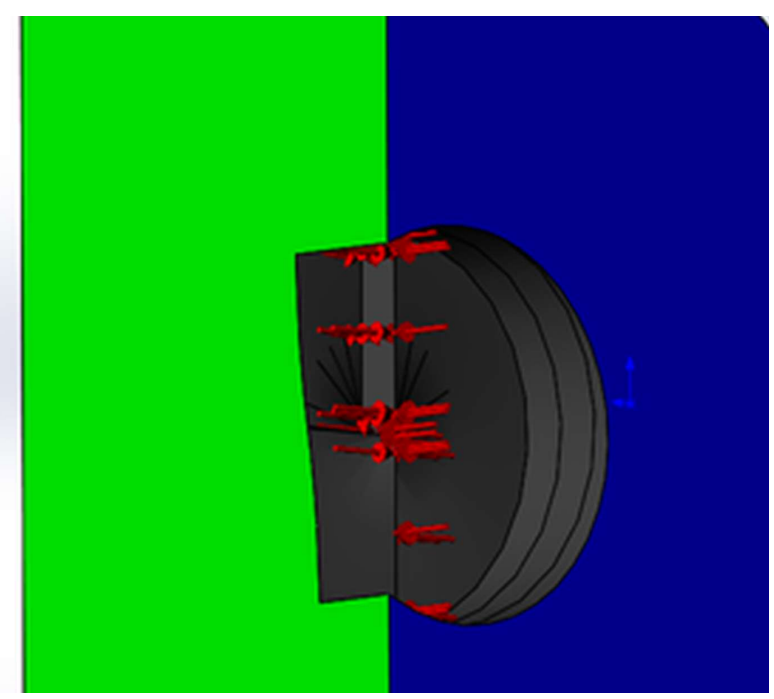

Fig. 3. Load Application. 


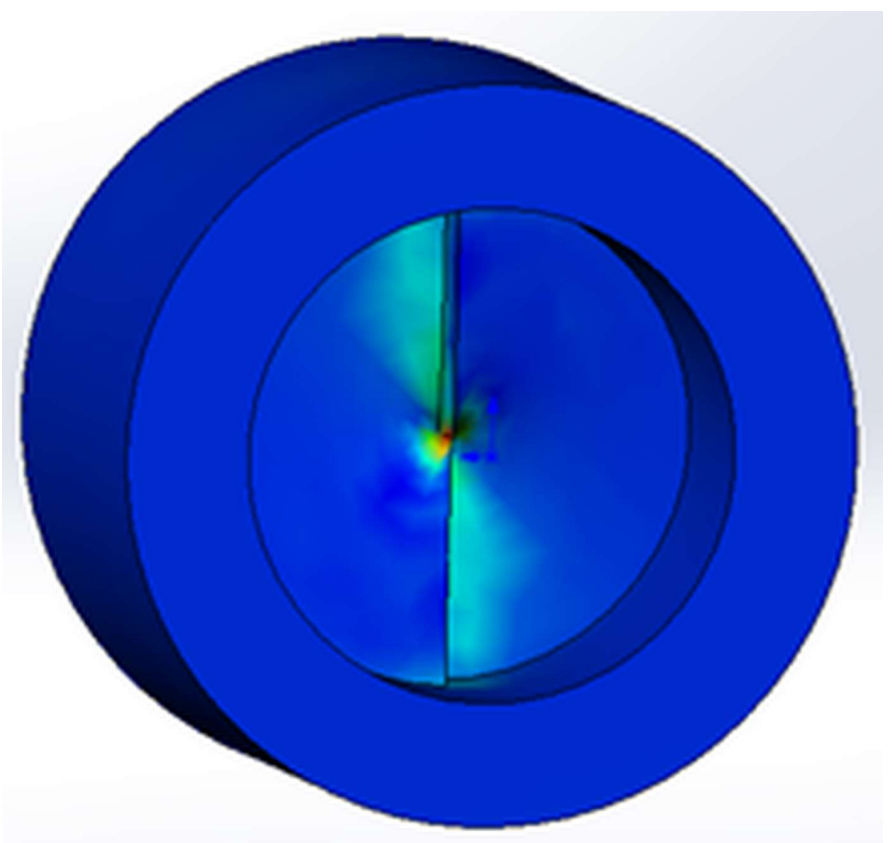

Fig. 4. Diagram of Principal Stresses $\sigma_{3}$.

The results of the modeling are given in Table 1.

Table 1. Values of stresses $\sigma_{3}$ on the model fixation surfaces and in the face space part of the array for different sizes of the beyond boundary array.

\begin{tabular}{|c|c|c|c|c|c|}
\hline \multirow{2}{*}{$\mathbf{B} / \mathbf{D}$} & \multicolumn{3}{|c|}{$\begin{array}{c}\text { Stresses } \boldsymbol{\sigma}_{3} \mathbf{2} \text { model fixation } \\
\text { surface }[\mathbf{k P a}]\end{array}$} & \multicolumn{2}{c|}{ Stresses $\boldsymbol{\sigma}_{3}$ in face space part (MPa) } \\
\cline { 2 - 6 } & $\sigma_{3 \max }$ & $\sigma_{3 \min }$ & difference & $\sigma_{3 \max }$ & $\sigma_{3 \min }$ \\
\hline 0.5 & 8.8 & -4.2 & 13 & 1.33 & -0.087 \\
\hline 1.0 & 3.4 & -1.3 & 4.7 & 1.34 & -0.095 \\
\hline 1.5 & 1.8 & -0.6 & 2.4 & 1.35 & -0.086 \\
\hline 2.0 & 1 & -0.3 & 1.3 & 1.35 & -0.07 \\
\hline 2.5 & 0.6 & -0.2 & 0.8 & 1.35 & -0.084 \\
\hline
\end{tabular}

\section{Conclusions}

Stress dependencies on the ratio of the thickness of the surrounding massif to the diameter of the working were chosenas criteria for the working estimation. The assessment was made on the following parameters: distribution irregularity of normal stresses on the fixed surfaces (difference $\sigma_{3 \max }-\sigma_{3 \min }$ ); stresses $\sigma_{3}$ in the area of application of the load (face space part).

Based on the conducted studies, it was revealed that with increasing thickness of the around boundary massif, the stresses at the fixation surfaces and the heterogeneity of their distribution (Fig. 5) decrease and for $\mathrm{B}>1.5 \mathrm{D}$ are incommensurably small compared to the stresses arising in the face space part;- at values $\mathrm{B}>1.5 \mathrm{D}$, the stress values in the face space part are practically independent of the thickness of the around boundary massif. 


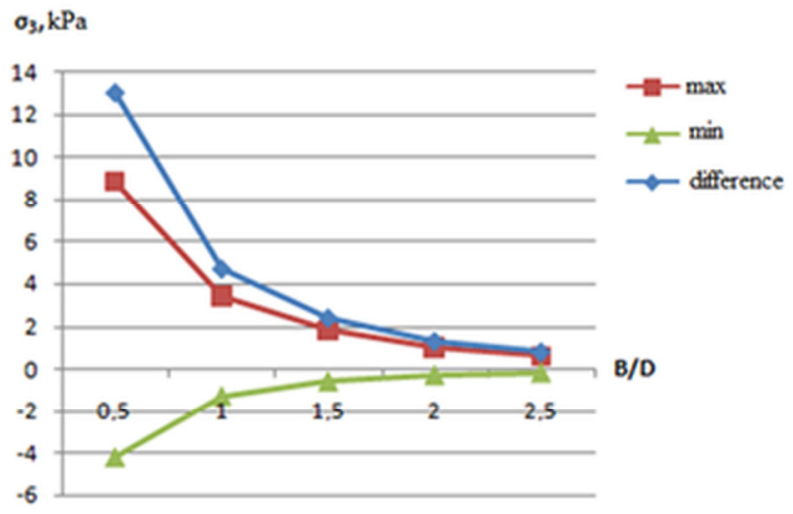

Fig. 5. Dependence of the Main Stresses $\sigma_{3}$ on the Model Fixation Surfaces on the Dimensions of the Around Boundary Massif.

On the basis of the obtained results, the thickness of the around boundary massif, equal to two diameters of working $(B=6.4 \mathrm{~m})$, was taken as sufficient.

\section{References}

1. S. Nishi, T. Seiki, Mem. Sch. Eng. Nagoya Univ, 1, 988 (1997)

2. B. Maid, L. Schmid, W. Ritz, M. Herrenknecht, Hardrock Tunnel Boring Machines (Ernst \& Sohn, Berlin, 2008)

3. T. Wighman, ENR: News - Rec., 4, 144-151 (1998)

4. V. Aksenov, V. Sadovets, D. Pashkov, E3S Web of Conferences, 21, 03008 (2017)

5. G. Brierley, World Tunnel. and subsurface Excav., 9, 01078 (1998)

6. A. B. Efremenkov, 6th International Forum on Strategic Technology (IFOST - 2011) 2:1, 348 (2011)

7. V. Aksenov, V. Sadovets, E. Rezanova, D. Pashkov, E3S Web Conf., 15, 03015 (2017)

8. A. V. Walter, V. V. Aksenov, Applied Mechanics and Materials, 770, 439 (2015)

9. J. Carmody, R. Sterling. Underground space design (Reinhold, New York, 1993)

10. V. Y. Sadovets, V. Y. Beglyakov, V. V. Aksenov, IOP Conference Series: Materials Science and Engineering, 91, 012085 (2015)

11. S. A. Zhironkin, A. A. Khoreshok, M. A. Tyulenev, G. A. Barysheva, M. C. Hellmer, IOP Conf. Ser.: Mater. Sci. Eng., 142, 012127 (2016)

12. M. Tyulenev, S. Zhironkin, K. Kolotov, E. Garina, Pollution Research, 35, 221 (2016)

13. V. Y. Begljakov, V. Y. Timofeev, M. V. Dokhnenko, Appl. Mech. Mater. 682, 282 (2014)

14. M. Y. Blashchuk, A. A. Kazantsev, R. V. Chernukhin, Appl. Mech. Mater., 682, 418 (2014)

15. Yu. V. Lesin, S. Yu. Luk'yanova, M. A. Tyulenev, J. Min. Sci., 46, 78 (2010)

16. A. A. Kazantsev, V. P. Kosykh, A. F. Revuzhenko, IOP Conference Series: Materials Science and Engineering, 91, 012089 (2015) 